\title{
Socio-Demographic Variation of Dementia Subtypes in China: Methodology and Results of a Prevalence Study in Beijing, Chengdu, Shanghai, and Xian
}

\author{
Zhen-Xin Zhang ${ }^{a, b}$ Gwendolyn E.P. Zahner ${ }^{a} \quad$ Gustavo C. Román $^{\text {h }}$ Xie-He Liu ${ }^{f}$ \\ Cheng-Bing Wu ${ }^{e}$ Zhen Hong $^{d}$ Xia Hong $^{\text {a, b }}$ Mao-Ni Tang ${ }^{f}$ Bing Zhou $^{d}$ \\ Qiu-Ming Qu ${ }^{\mathrm{e}}$ Xiao-Jun Zhang ${ }^{g}$ Hui Lic \\ Departments of ${ }^{\mathrm{a} C l i n i c a l}$ Epidemiology and ${ }^{\mathrm{b}}$ Neurology, Peking Union Medical College Hospital, and \\ 'Department of Epidemiology, Peking Union Medical College, Beijing, d Department of Neurology, \\ Huashan Hospital, Fudan University, Shanghai, e Department of Neurology, The First Hospital, Xian University, Xian, \\ fDepartment of Psychiatry, The First Hospital, Huaxi Medical College, Chengdu, and ' Department of Neurology, \\ Tongren Hospital, Beijing, PR China; h Department of Medicine/Neurology, University of Texas Health Science Center, \\ San Antonio, Tex., USA
}

\section{Key Words}

Alzheimer's disease $\cdot$ Vascular dementia •

Sociodemographics $\cdot$ China

\begin{abstract}
Objective: To characterize sociodemographic variations in the prevalence of AD and VaD in China. Methods: Data were collected in a 1997-1998, cross-sectional, door-to-door prevalence survey of 34,807 community residents ages $\geq 55$ years in Beijing, Shanghai, Chengdu and Xian. Initial diagnoses of $A D$ and $V a D$ were assessed by clinicians using standardized protocols, according to the NINCDS-ADRDA and NINDS-AIREN criteria; diagnoses were confirmed after 6 months by repeating neuropsychological evaluations. Prevalence odds ratios were estimated in logistic models adjusting for survey design, age, and other sociodemographic factors. Results: We identified 732 prevalent cases of AD and 295 cases of VaD. Adjusting for all sociodemographic factors concurrently, prevalence odds of $A D$ and VaD were higher in northern versus southern China. Age trends for $A D$ appeared different in western and eastern China. AD also showed an age-adjusted elevation among women and, in the fully ad-
\end{abstract}

justed model, a gender education interaction indicating a female preponderance in the highest education group. North-south variation for $\mathrm{VaD}$ was age-dependent. In the fully adjusted model, for $A D$, widowed had significantly higher prevalence odds; for $\mathrm{VaD}$, widowed persons and minorities had significantly lower prevalence odds; professionals had statistically significant and borderline lower prevalence odds for both $\mathrm{VaD}$ and $\mathrm{AD}$; sales-service occupations had significantly lower odds for AD only. Conclusion: We observed variations in prevalence for $A D$ and $\mathrm{VaD}$ in different regions and demographic groups in China that persisted after controlling for potential confounding factors. Sociodemographic factors are probable surrogates for conditions such as lifestyle, environment, comorbidities, and life expectancy.

Copyright $\odot 2006$ S. Karger AG, Basel

\section{Introduction}

Worldwide, the number of elderly people in developing nations currently exceeds that of industrialized nations. Projections from the World Health Organization

\section{KARGER}

Fax +41613061234 E-Mail karger@karger.ch www.karger.com (c) 2006 S. Karger AG, Basel

0251-5350/06/0274-0177\$23.50/0

Accessible online at:

www.karger.com/ned
Dr. Zhen-Xin Zhang

Department of Neurology, Peking Union Medical College Hospital

Chinese Academy of Medical Sciences

Beijing 100730 (PR China)

Tel. +86106529 5095, Fax +86106512 4875, E-Mail zhangzx@pumch.cn 
indicate a trend towards further aging of developing countries [1]. Nonetheless, there is a dearth of epidemiological data in developing countries on diseases of aging including dementia [2].

Population-based epidemiological studies in Western countries report minimal geographic variation in the prevalence of the two major dementia subtypes, Alzheimer's disease $(\mathrm{AD})$ and vascular dementia $(\mathrm{VaD})$ [3-7]. In comparison, previous prevalence studies in China and other East Asian countries have reported lower figures than those of Europe and North America [8-14], as well as different patterns in the frequency of the major subtypes seen in East Asia. Whereas AD predominates in Europe and North America, an excess of $\mathrm{VaD}$ over $\mathrm{AD}$ has been reported in Japan and Northern China $[11,15]$. Although methodological factors such as completeness of case ascertainment could explain this variation, most investigators believe that differences in ethnic, cultural and socioeconomic could modify the underlying risk factors for dementia explaining the differences observed in East Asian populations. Many of these factors may be changing with economic development in different nations and regions in this part of the world $[16,17]$.

Previously, we reported our findings from a large multicenter, population-based study of dementia in China indicating that the overall prevalences of $\mathrm{AD}$ and $\mathrm{VaD}$ currently approximate those of Western countries [18]. We provide here a detailed account of our study methodology and report sociodemographic variations in the prevalence of $\mathrm{AD}$ and $\mathrm{VaD}$ within China in four large and diverse regional centers: Beijing (northeast), Xian (northwest), Shanghai (southeast), and Chengdu (southwest).

\section{Methods}

\section{Study Areas}

The four areas of China studies in this project were selected to represent regional variations in environmental conditions, natural resources, economic development, diet, culture, and lifestyle. These four regional centers cover a total of 34 urban districts and 36 rural counties. In 1994, the total population of these four centers was 39.6 million, and the proportion of elderly persons aged 65 years and older was $7.7 \%$ in Beijing, $11.5 \%$ in Shanghai, $6.8 \%$ in Chengdu, and 5.3\% in Xian. The life expectancy at birth is longer in eastern China (72.9 years in Beijing, 74.9 years in Shanghai) than in the west (67.4 years in Xian, 66.3 years in Chengdu) [19]. In general, China's northern regions (Beijing, Xian) have more severe climate than the southern areas near the Yangtze River basin (Chengdu, Shanghai). Eastern China (Beijing, Shanghai) is more economically developed than western China (Xian, Chengdu). China has experienced an exponential economic growth in the last few decades. In 1994, the value of gross annual industrial output (in billion Yuan - in 1994, USD 1 equalled approximately Chinese Yuan 8.27) was 20.4 in Beijing, 42.6 in Shanghai, 10.3 in Chengdu, and 3.9 in Xian. The corresponding figures for agriculture were $14.4,14.0,12.8$ and 5.7 [19].

\section{Target Population}

The target population consisted of all persons ages $\geq 55$ years in 1997 living in the administrative regions of Beijing, Shanghai, Chengdu, and Xian. Eligible persons for inclusion in the study were residents who: (1) were listed in the 1996 population census of community registry offices (CROs) and who resided in the community of registration in the year preceding the survey date; or (2) were not listed in the CRO, but resided for at least one year preceding the survey date in the household of first degree relatives who were registered in the CRO; or (3) were current residents of a chronic care home listed in the CRO on the survey date. We excluded residents who were unregistered or who lived with registered relatives for less than 1 year, and persons on the 1996 registration lists who had been absent from the community in the month preceding the survey date.

\section{Sampling Procedures}

The sample was drawn according to a stratified, multistage, cluster sampling design. Fifteen super-strata were formed corresponding to the four regional centers and rural-suburban-urban counties and districts subsumed within each region. Using tables of random numbers to choose elements within each superstratum, we selected a total of 14 predominantly urban districts and 19 predominantly rural counties as the first sampling stage. Within these counties/districts, a random sample of urbanized sectors $(\mathrm{n}=37)$ and rural townships $(\mathrm{n}=53)$ were chosen, followed by a random sample of urbanized communities $(n=76)$ and rural villages $(\mathrm{n}=106)$ within the chosen sectors/townships. In each sampled community, an updated CRO population list for 1996 was obtained. A total of 34,807 persons met the eligibility criteria, and were invited to participate in the study.

\section{Clinical Interviewer Training}

A total of 63 interviewers, including university hospital neurologists, neuroepidemiologists, neuropsychologists, psychiatrists, and medical students, were recruited from the four regional centers and were grouped into working teams by region. Each regional fieldwork team included two or more senior clinicians (total $=14 ; 22 \%$ of interviewers) and three or more mid-level clinicians (total $=19 ; 30 \%$ of interviewers). The supervisor and two other interviewers from each team received 1-week training on the study protocol in Beijing, followed by 1-2 weeks of community fieldwork with the team headed by the lead hospital (PUMCH) in Beijing. The rest of the clinical field interviewers were trained by their supervisor at the regional sites. All interviewers completed a pilot study in a nonsampled community in their own region before engaging in fieldwork. At the completion of training, the inter-rater reliability of the Chinese mini-mental status examination (C-MMSE) [20] and of other cognitive tests was assessed using ratings of a videotaped model interview. Inter-rater reliability coefficients (correlations) of the C-MMSE for all field interviewers exceeded.90. To ensure consistency over time and place, post-training sessions were held every 6 months, and the Principal Investigator and supervisors closely monitored fieldwork in all regions during the study. 


\section{Recruitment and Informed Consent}

Participation in the population survey was voluntary and involved multiple levels of approval by collaborating hospitals and community leaders at regional and local levels. Approvals were obtained before community residents were contacted for the study. In each randomly selected community or village, an initial meeting was held with community leaders to explain the purpose of the study. The community leaders were shown documents from the Chinese Science and Technology Research Board (CSTRB) approving the ethical and safety standards of the research procedures, and, as necessary, additional authorization by local hospitals or regional health officials. After local leaders granted permission, flyers describing the study were posted in participating neighborhoods. Announcements about the study were also made in local civic meetings. Participation in the survey was encouraged but it was emphasized that individuals were free to refuse to participate without untoward consequences. Consent to participate was obtained orally.

Using standard survey procedures, eligible households were contacted door-to-door up to three times by clinical researchers who were trained in the CSTRB-approved fieldwork procedures. Because elderly persons are often reluctant to be interviewed by young physicians or medical students, a senior research physician routinely visited the home after an initial refusal to determine the potential respondent's final interest in enrolling in the study and reasons for nonparticipation. At later intervals, clinical researchers also returned to communities to seek eligible persons who had not been located earlier or to trace individuals living in nursing homes outside the study area. Participation rates for screening interviews with eligible respondents in the randomly sampled communities ranged from $73 \%$ to $100 \%$, and averaged $94 \%$ for all communities in the study.

\section{Diagnostic Assessment Procedures}

A door-to-door multiphase diagnostic assessment protocol was used for case ascertainment. A detailed flow chart of dementia assessment procedures is given in Zhang et al. [18]. The main steps are summarized below.

Phase I: Dementia Screening. Phase I involved a door-to-door screening survey conducted by teams of trained clinical interviewers. All phase I participants were administered the following tests: C-MMSE [20, 21], activities of daily life (ADL) [22, 23], Dementia Symptom List [24], and a questionnaire eliciting demographic information, personal and medical history, family history for dementia in first-degree relatives, and a brief physical and neurological examination. The C-MMSE cut-points were established in a population-based pilot study conducted by the lead hospital in Beijing [20]. The optimal C-MMSE cut-points were the lowest 10th percentile scores for three different educational levels: $\leq 19$ for those with no formal education, $\leq 22$ for those with $\leq 6$ years of education, and $\leq 26$ for those with $7+$ years of education. Screening validity of these cut-points was confirmed in the Beijing pilot study in 76 patients with clinically demonstrated dementia and 1,878 nondemented urban subjects (sensitivity = $90.8 \%$, specificity $=93 \%$, positive predictive value $(\mathrm{PPV})=34.3$, negative predictive value $(\mathrm{NPV})=99.6)[20]$. Screening interviews were completed in 34,807 elders, including 8,694 in Beijing, 4,850 in Xian, 15,910 in Shanghai and 5,353 in Chengdu. The sample included only 80 persons $(0.2 \%)$ in nursing homes.

Socio-Demographic Variation of

Dementia Subtypes in China
Phase II: Preliminary Clinical Diagnostic Assessment. Phase II yielded a preliminary diagnosis for persons with possible and probable dementia. Phase II interviews were conducted with persons scoring below the cut-point on the C-MMSE for their educational level and all those who could not complete the screening tests. Following a standard protocol, clinical interviewers collected detailed medical histories, conducted standard neurological examinations, and performed a set of conventional neuropsychological tests to assess memory, language, attention, orientation, visual perception, construction, and executive function, using the following instruments: the Fuld Object Memory Test [25], Category Verbal Fluency Test [26], Block Design Subset of Wechsler Intelligence Scale for Children-Revised [27], and Digit Span of the Wechsler Adult Intelligence Scale [28]. When these conventional neuropsychological assessments did not yield a confirmed diagnosis of cognitive impairment, additional assessments were undertaken using the Clinical Dementia Rating Scale [29], the Chinese Clinical Memory Scale [30], and the Clock Drawing Test [31]. The Hamilton Depression Rating Scale [32], the Neuropsychiatric Inventory [33], and Hachinski's ischemic scale [34] were completed to distinguish AD from related dementing disorders. The Global Deterioration Scale (GDS) was used to classify dementia severity [35]. Interference with social or professional life was assessed with the Pfeffer questionnaire [36]. Proxy (caregiver) interviews were completed when some physical impairment, illness, or severe dementia prevented the respondent from completing the standard neuropsychological test. A caregiver questionnaire developed in an earlier Shanghai study [37] was used to identify cognitive impairment in these persons.

During the evening of each workday, the clinical interviewing teams held a clinical conference to review each set of examination results. Diagnoses were made independently by each clinician according to the standardized criteria described below. In case of discordant diagnoses or when further evidence of cognitive impairment was needed for differential diagnosis of dementia subtype, a senior clinician returned to the household the following day to reexamine respondents with supplemental neuropsychological tests. If a diagnosis could still not be confirmed, the participant was referred to a research hospital for further evaluation.

Of the 34,807 persons who completed screening interviews, a total of 3,950 screened positive and were enrolled in phase II. About $2 / 3$ of them $(n=2,476 ; 62.7 \%)$ received the standardized phase II neuropsychological assessment; the remainder were assessed with caregiver interviews ( $\mathrm{n}=1,474,37.3 \%)$.

Phase III: 6-Month Diagnostic Confirmation. The validity of the diagnosis was confirmed by re-examination at least 6 months after the phase II assessment. All the aforementioned screening tests and diagnostic examinations were re-administered to every phase II participant exhibiting partial evidence of dementia that volunteered for re-examination and could be traced. If a proxy examination was completed in phase II but the participant's disability had remitted at the time of the phase III examination, the participant was asked to complete the C-MMSE to determine whether conventional neuropsychological assessments would be undertaken. Phase III clinical re-assessments were completed for 3,504 persons $(88.7 \%)$.

Final Diagnoses. The final diagnoses were made by the senior research physicians in a conference at each site after the phase III examination. The final diagnosis was based on all available data, including complete history, examination findings, test results, 
temporal course, and relevant medical documentation or laboratory tests. If respondents were lost to follow-up at any phase, the final diagnoses were based on all available clinical data from earlier clinical examinations and tests. CT/MRI was not used routinely for the differential diagnosis of dementia subtypes.

\section{Diagnostic Criteria for Classification of Dementia Subtypes}

The diagnostic criteria used in this study were the NINCDSADRDA [38] for probable or possible AD, and the NINCDS-AIREN [39] for probable or possible VaD. The NINCDS-AIREN criteria identify patients with clinical and/or neuroimaging evidence of cerebral infarctions contributing to dementia, as well as dementia syndromes following a recognized cerebrovascular event (poststroke $\mathrm{VaD}$ ). It excludes concomitant processes other than dementia from cerebrovascular disease (CVD). This group also includes persons for whom there was no clear temporal relationship between stroke and dementia, or persons who had a subtle onset and variable course, but displayed evidence of relevant CVD (from neuroimaging studies, if available). If the relationship between stroke and dementia was indistinct, we required at least two ischemic episodes by history, with a positive neurological examination or neuroimaging studies. Based on the characteristics of CVD and its relationship to cognitive functions, these patients were classified by the NINCDS-AIREN for probable or possible VaD. The Hachinski score was also used as a reference to identify $\mathrm{VaD}$ cases.

Using DSM-IV [40] and ICD-10 [41] criteria as well as other previously published descriptions, we excluded other causes of dementia, such as normal pressure hydrocephalus, Lewy body dementia, progressive supranuclear palsy, and the fronto-temporal dementias. Exclusions also encompassed diagnoses of depression or other psychiatric disorders assessed by the brief psychiatric interview and the Hamilton Depression Rating Scale [32]. Persons with depression or mental retardation were excluded from all dementia diagnostic ratings.

\section{Cases Missed by C-MMSE Screening}

To determine how many cases may have been missed by the C-MMSE screen, we estimated the predictive value of negative screening scores $(\mathrm{PVN})$ in a random sample of $3-4 \%$ of participants at each center who screened negative in phase I. A total of 1,008 persons (3.2\%) were randomly selected from the $30,857 \mathrm{C}$ MMSE screen negatives in phase I. These subjects received the full phase II/III diagnostic assessments by clinical raters who were blind to their initial screening status. The PVN of the C-MMSE was found to be $97.6 \%$ for $\mathrm{AD}$ and $99.7 \%$ for $\mathrm{VaD}$. Controlling for age-gender-and education differences across sites, site-specific variation in screening sensitivity for dementia was found at only one center (Chengdu), which underdiagnosed dementia compared to other sites (Wald test $=6.095$, d.f. $=1, \mathrm{p}=0.14$ ).

\section{Statistical Analysis}

All analyses were survey design-based and were conducted using the SUDAAN Version 8.0 [42] sample survey software. For purposes of analysis, the survey was treated as a stratified, two stage design. Because several first stage districts and counties were chosen with certainty (thereby precluding variance estimation), urbanized sectors and rural townships served as the Primary Sampling Units (PSU's). Weights were formed by multiplying selection probabilities of the three sampling stages together with the inverse of the participation rate among eligible persons ages $\geq 55$ in each sampled community. Weight distributions were examined within each regional center for outliers, and clusters with weights exceeding the 95th quantile were combined with nearest neighbors in order to smooth the weight distributions. Estimates of sample characteristics, including means and proportions, were weighted to the target population; frequencies were scaled to the original sample size. Standard errors (SE) were estimated using Taylor series and are consistent with the sample design.

We examined sociodemographic variation and potential confounding in logistic regression models using SUDAAN Proc Logist. Prevalence odds ratios (pOR) and 95\% confidence intervals (CI) accounting for sampling design and confounding by covariates were calculated from model coefficients. Separate logistic models were developed for $\mathrm{AD}$ and $\mathrm{VaD}$. In each model, illness status (prevalent case/non case) was the outcome (dependent) variable; sociodemographic factors were the predictor (independent) variables. Our models included factors that were previously reported to be associated with risk or prognosis of $\mathrm{AD}$ or $\mathrm{VaD}$, including regional effects (north-south and east-west contrasts), gender, age (10-year intervals), ethnicity (Han Chinese versus other), rural-urban residence, occupation (farmer, non-farm laborer, government administrator, professional manager, sales service, housewife), marital status (married, widowed, other), and education $(<1,1-6,7-11,12+$ years).

We adjusted for different levels of confounding in separate logistic models using increasingly stringent controls. Crude (unadjusted) associations between socio-demographic factors and dementia outcome were estimated by entering each socio-demographicfactor individually as predictor variable without covariates $\left(\mathrm{pOR}_{\text {unadj }}\right)$. To compute age-adjusted associations ( $\left.\mathrm{pOR}_{\text {age-adj }}\right)$ we used logistic models entering each socio-demographic factor with age in 10-year intervals. To control for confounding among all demographic variables we estimated fully-adjusted prevalence odds ratios $\left(\mathrm{pOR}_{\text {full-adj }}\right)$ in multivariable models with all regional effects and sociodemographic factors as predictor variables. Tests of interactions between all characteristics with age and gender were performed in fully adjusted logistic models with forward, stepwise selection. Only statistically significant $(\mathrm{p}<0.05)$ interactions were retained in the final, fully adjusted model.

\section{Results}

Table 1 summarizes the major characteristics of the study sites. All sociodemographic characteristics displayed statistically significant regional variation $(\mathrm{p}<$ 0.01 ), except gender. Age showed significant north-south variation, with proportionately more persons $\geq 65$ years in southern compared to northern regions. The western regions had significantly more laborers (farm and nonfarm), rural residents, persons with no formal education, and widows than the eastern centers. The sample was almost entirely (>98\%) represented by the ethnic group Han Chinese.

A total of 732 cases of $\mathrm{AD}$ and 295 cases of $\mathrm{VaD}$ were identified in the final diagnoses. CT/MRI was used in 
Table 1. Characteristics of the study population in four regional centers of China

\begin{tabular}{|c|c|c|c|c|c|c|c|c|c|c|c|c|c|c|c|}
\hline \multirow{2}{*}{$\begin{array}{l}\text { Characteristic } \\
\text { Total sample }\end{array}$} & \multicolumn{3}{|c|}{$\begin{array}{l}\text { Beijing } \\
\text { (N.E. region) }\end{array}$} & \multicolumn{3}{|c|}{$\begin{array}{l}\text { Xian } \\
\text { (N.W. region) }\end{array}$} & \multicolumn{3}{|c|}{$\begin{array}{l}\text { Shanghai } \\
\text { (S.E. region) }\end{array}$} & \multicolumn{3}{|c|}{$\begin{array}{l}\text { Chengdu } \\
\text { (S.W. region) }\end{array}$} & \multicolumn{3}{|l|}{ Total } \\
\hline & $\%$ & $\mathrm{SE}$ & $\begin{array}{l}\mathrm{n} \\
8,694\end{array}$ & $\%$ & SE & $\begin{array}{l}\mathrm{n} \\
4,850\end{array}$ & $\%$ & SE & $\begin{array}{l}\mathrm{n} \\
15,910\end{array}$ & $\%$ & SE & $\begin{array}{l}\mathrm{n} \\
5,353\end{array}$ & $\%$ & SE & $\begin{array}{l}\mathrm{n} \\
34,807\end{array}$ \\
\hline \multicolumn{16}{|l|}{ Sex } \\
\hline Men & 47.0 & 0.7 & 3,974 & 43.9 & 1.6 & 2,040 & 45.9 & 1.3 & 7,183 & 46.6 & 1.0 & 2,552 & 46.2 & 0.6 & 15,749 \\
\hline Women & 53.0 & 0.7 & 4,720 & 56.1 & 1.6 & 2,810 & 54.1 & 1.3 & 8,727 & 53.4 & 1.0 & 2,801 & 53.8 & 0.6 & 19,058 \\
\hline \multicolumn{16}{|l|}{ Age } \\
\hline $55-64$ & 50.4 & 4.0 & 4,203 & 48.6 & 1.4 & 2,222 & 37.5 & 3.0 & 5,521 & 39.6 & 1.8 & 2,206 & 43.7 & 1.8 & 14,152 \\
\hline $65-74$ & 37.0 & 3.2 & 3,186 & 35.3 & 1.3 & 1,780 & 41.5 & 1.0 & 6,744 & 40.9 & 1.7 & 2,083 & 39.2 & 1.3 & 13,793 \\
\hline $75-84$ & 10.9 & 1.2 & 1,117 & 14.7 & 0.9 & 769 & 17.4 & 1.7 & 3,030 & 15.6 & 2.4 & 862 & 14.4 & 0.8 & 5,778 \\
\hline $85+$ & 1.7 & 0.3 & 188 & 1.4 & 0.2 & 79 & 3.6 & 0.4 & 615 & 3.8 & 0.4 & 202 & 2.7 & 0.2 & 1,084 \\
\hline \multicolumn{16}{|l|}{ Education, years } \\
\hline$<1$ & 31.0 & 5.6 & 3,235 & 52.1 & 5.5 & 2,448 & 34.6 & 4.7 & 5,518 & 42.0 & 4.6 & 2,405 & 36.1 & 2.8 & 13,606 \\
\hline $1-6$ & 28.2 & 5.1 & 2,696 & 27.3 & 1.1 & 1,392 & 32.3 & 1.5 & 5,040 & 43.4 & 2.2 & 2,360 & 32.1 & 2.1 & 11,488 \\
\hline $7-12$ & 19.4 & 2.9 & 1,610 & 16.4 & 2.7 & 833 & 25.5 & 3.0 & 4,081 & 12.9 & 2.6 & 537 & 20.4 & 1.8 & 7,061 \\
\hline $12+$ & 21.5 & 9.6 & 1,153 & 4.2 & 2.6 & 177 & 7.5 & 1.5 & 1,271 & 1.7 & 0.5 & 51 & 11.5 & 3.7 & 2,652 \\
\hline Unknown & 0.0 & 0.0 & 0 & 0.0 & 0.0 & 0 & 0.0 & 0.0 & 0 & 0.0 & 0.0 & 0 & 0 & 0 & 0 \\
\hline \multicolumn{16}{|l|}{ Residence } \\
\hline Rural & 24.2 & 9.6 & 3,599 & 69.9 & 10.5 & 2,958 & 30.1 & 13.0 & 4,882 & 56.0 & 12.0 & 3,731 & 35.7 & 6.7 & 15,170 \\
\hline Urban & 75.8 & 9.6 & 5,095 & 30.1 & 10.5 & 1,892 & 69.9 & 13.0 & 11,028 & 44.0 & 12.0 & 1,622 & 64.3 & 6.7 & 19,637 \\
\hline \multicolumn{16}{|l|}{ Marital status } \\
\hline Married & 82.0 & 2.1 & 6,691 & 70.0 & 2.2 & 3,377 & 77.7 & 1.8 & 12,159 & 70.3 & 3.7 & 3,683 & 77.4 & 1.4 & 25,910 \\
\hline Widowed & 16.6 & 2.0 & 1,827 & 28.7 & 2.2 & 1,411 & 20.4 & 1.7 & 3,394 & 27.1 & 3.9 & 1,530 & 20.8 & 1.3 & 8,162 \\
\hline Other & 1.2 & 0.2 & 128 & 1.3 & 0.2 & 62 & 1.9 & 0.2 & 352 & 2.4 & 0.3 & 134 & 1.6 & 0.1 & 676 \\
\hline Unknown & 0.3 & 0.2 & 48 & 0.0 & 0.0 & 0 & $<0.1$ & $<0.1$ & 5 & 0.2 & $<0.1$ & 6 & 0.1 & 0.1 & 59 \\
\hline \multicolumn{16}{|l|}{ Ethnicity } \\
\hline Han & 97.1 & 0.5 & 8,408 & 99.4 & 0.2 & 4,817 & 99.6 & 0.1 & 15,831 & 99.7 & 0.1 & 5,337 & 98.6 & 0.2 & 34,393 \\
\hline Meng, Hui, other & 2.9 & 0.5 & 286 & 0.5 & 0.2 & 32 & 0.4 & 0.1 & 79 & 0.3 & 0.1 & 16 & 1.3 & 0.2 & 413 \\
\hline Unknown & 0 & 0 & 0 & $<0.1$ & $<0.1$ & 1 & 0.0 & 0.0 & 0 & 0.0 & 0.0 & 0 & $<0.1$ & $<0.1$ & 1 \\
\hline \multicolumn{16}{|c|}{ Occupation(prior to retirement) } \\
\hline Farm laborer & 20.8 & 7.5 & 3,165 & 65.8 & 9.6 & 2,796 & 27.1 & 9.6 & 4,473 & 52.9 & 11.7 & 3,525 & 32.5 & 5.3 & 13,959 \\
\hline Non-farm laborer & 33.9 & 11.3 & 2,488 & 14.2 & 3.8 & 917 & 46.7 & 6.9 & 7,129 & 30.9 & 9.1 & 1,202 & 36.4 & 5.3 & 11,736 \\
\hline \multicolumn{16}{|l|}{ Government, military } \\
\hline official & 16.0 & 4.1 & 1,075 & 9.0 & 4.1 & 448 & 9.4 & 1.7 & 1,483 & 6.4 & 2.6 & 209 & 11.4 & 1.6 & 3,215 \\
\hline Professional, managerial & 20.4 & 9.5 & 1,186 & 4.3 & 1.5 & 210 & 8.8 & 1.7 & 1,434 & 3.0 & 1.0 & 98 & 11.8 & 3.6 & 2,928 \\
\hline Sales, servic & 1.8 & 0.5 & 185 & 1.5 & 0.2 & 113 & 3.7 & 0.6 & 682 & 2.3 & 0.8 & 119 & 2.6 & 0.3 & 1,099 \\
\hline Housework & 7.0 & 1.1 & 588 & 5.1 & 0.8 & 366 & 4.2 & 0.2 & 709 & 4.5 & 1.6 & 200 & 5.4 & 0.6 & 1,863 \\
\hline Unknown & 0.2 & 0.1 & 7 & 0.0 & 0.0 & 0 & 0 & 0 & 0 & 0.0 & 0.0 & 0 & 0.3 & 0.2 & 7 \\
\hline \multicolumn{16}{|l|}{ Dementia } \\
\hline $\mathrm{AD}$ & 1.8 & 0.2 & 177 & 2.0 & 0.2 & 99 & 2.2 & 0.2 & 328 & 2.2 & 0.1 & 128 & 2.0 & 0.1 & 732 \\
\hline $\mathrm{VaD}$ & 1.1 & 0.2 & 121 & 1.2 & 0.2 & 51 & 0.6 & 0.1 & 98 & 0.4 & $<0.1$ & 25 & 0.8 & 0.1 & 295 \\
\hline
\end{tabular}

All percents are weighted to the target population.

half (50.9\%) of cases diagnosed as $\mathrm{VaD}$ and but only in $6.8 \%$ of $\mathrm{AD}$ cases. As expected, the mean HIS for $\mathrm{AD}$ $(1.5, \mathrm{n}=531)$ was lower than for $\operatorname{VaD}(10.4, \mathrm{n}=230)$. The proportion of the population older than 65 years with $\mathrm{AD}$ ranged from 1.8 to $2.2 \%$ across the four regions, and was $2.0 \%$ for all regions combined. For VaD, the corre- sponding regional range was $0.4-1.2 \%$, and was $0.8 \%$ overall in the study population. Zhang et al. [18] provides additional details about $\mathrm{AD}$ and $\mathrm{VaD}$ prevalences, including age standardization and adjustment for screening errors. 
Table 2. Logistic regression analysis of sociodemographic predictors of Alzheimer's dementia in China ${ }^{1}$

\begin{tabular}{|c|c|c|c|c|c|c|c|c|c|}
\hline Independent vari & les and effects & \multirow[t]{2}{*}{$\begin{array}{l}\text { Number } \\
\text { of AD } \\
\text { cases }\end{array}$} & \multirow{2}{*}{$\begin{array}{l}\text { Prevalence } \\
\text { rate weighted } \\
\text { by cluster } \\
\text { sample, \% }\end{array}$} & \multicolumn{2}{|c|}{$\begin{array}{l}\text { Model I: no covariate } \\
\text { adjustment }^{2}\end{array}$} & \multicolumn{2}{|c|}{$\begin{array}{l}\text { Model II: } \\
\text { age adjusted }^{3}\end{array}$} & \multicolumn{2}{|c|}{$\begin{array}{l}\text { Model III: full co-variate } \\
\text { adjustment and significant } \\
(p<0.05) \text { interaction terms }\end{array}$} \\
\hline & & & & OR & $95 \%$ CI & OR & $95 \%$ CI & OR & $95 \% \mathrm{CI}$ \\
\hline \multirow{4}{*}{ Age group, years } & 55-64 (ref.) & 29 & 0.2 & 1.0 & $1.0,1.0$ & & & 1.0 & $1.0,1.0$ \\
\hline & $65-74$ & 155 & 1.2 & 6.7 & $3.9,11.6$ & & & 5.2 & $2.9,9.4$ \\
\hline & $75-84$ & 328 & 5.8 & 33.1 & $17.5,62.7$ & & & 20.6 & $10.3,41.3$ \\
\hline & $85+$ & 220 & 23.3 & 164.6 & $84.2,321.8$ & & & 82.9 & $36.9,186.1$ \\
\hline \multirow[t]{2}{*}{ Gender } & male (ref.) & 218 & 1.3 & 1.0 & $1.0,1.0$ & 1.0 & $1.0,1.0$ & 1.0 & $1.0,1.0$ \\
\hline & female & 514 & 2.6 & 2.0 & $1.5,2.5$ & 1.9 & $1.4,2.4$ & 1.3 & $0.9,1.8$ \\
\hline \multirow[t]{4}{*}{ Education, years } & $<1$ (ref.) & 512 & 3.9 & 1.0 & $1.0,1.0$ & 1.0 & $1.0,1.0$ & 1.0 & $1.0,1.0$ \\
\hline & $1-6$ & 129 & 1.1 & 0.3 & $0.2,0.4$ & 0.5 & $0.4,0.6$ & 0.6 & $0.4,1.0$ \\
\hline & $7-12$ & 69 & 1.0 & 0.2 & $0.2,0.4$ & 0.5 & $0.4,0.7$ & 0.6 & $0.3,1.0$ \\
\hline & $12+$ & 22 & 0.7 & 0.2 & $0.1,0.3$ & 0.4 & $0.2,0.8$ & 0.6 & $0.3,1.3$ \\
\hline \multirow[t]{2}{*}{ Residence } & urban (ref.) & 370 & 1.7 & 1.0 & $1.0,1.0$ & 1.0 & $1.0,1.0$ & 1.0 & $1.0,1.0$ \\
\hline & rural & 362 & 2.6 & 1.5 & $1.2,1.8$ & 1.4 & $1.2,1.7$ & 1.0 & $0.7,1.5$ \\
\hline \multirow[t]{3}{*}{ Marital status } & married (ref.) & 280 & 1.0 & 1.0 & $1.0,1.0$ & 1.0 & $1.0,1.0$ & 1.0 & $1.0,1.0$ \\
\hline & widowed & 438 & 5.4 & 5.2 & $4.0,6.8$ & 1.7 & $1.4,2.2$ & 1.4 & $1.1,1.7$ \\
\hline & other & 11 & 2.5 & 2.3 & $1.0,5.3$ & 1.9 & $0.7,4.8$ & 2.0 & $0.8,5.0$ \\
\hline \multirow[t]{2}{*}{ Ethnicity } & Han (ref.) & 725 & 2.0 & 1.0 & $1.0,1.0$ & 1.0 & $1.0,1.0$ & 1.0 & $1.0,1.0$ \\
\hline & other & 7 & 1.1 & 0.5 & $0.2,1.4$ & 0.6 & $0.3,1.3$ & 0.6 & $0.3,1.4$ \\
\hline \multirow[t]{6}{*}{ Occupation } & farm laborer (ref.) & 358 & 2.8 & 1.0 & $1.0,1.0$ & 1.0 & $1.0,1.0$ & 1.0 & $1.0,1.0$ \\
\hline & non-farm laborer & 204 & 1.7 & 0.6 & $0.4,0.8$ & 0.7 & $0.5,1.0$ & 0.9 & $0.5,1.5$ \\
\hline & official & 30 & 0.9 & 0.3 & $0.2,0.5$ & 0.5 & $0.3,0.9$ & 0.7 & $0.3,1.5$ \\
\hline & professional & 25 & 0.6 & 0.2 & $0.1,0.3$ & 0.4 & $0.2,0.8$ & 0.4 & $0.2,1.0$ \\
\hline & sales, service & 13 & 1.1 & 0.4 & $0.2,0.7$ & 0.3 & $0.2,0.6$ & 0.4 & $0.2,1.0$ \\
\hline & housework & 102 & 5.7 & 2.1 & $1.3,3.4$ & 1.0 & $0.7,1.5$ & 0.9 & $0.5,1.6$ \\
\hline \multirow[t]{2}{*}{ Region } & north & 276 & 1.8 & 0.8 & $0.7,1.1$ & 1.3 & $1.0,1.7$ & 1.3 & $1.0,1.7$ \\
\hline & south (ref.) & 456 & 2.2 & 1.0 & $1.0,1.0$ & 1.0 & $1.0,1.0$ & 1.0 & $1.0,1.0$ \\
\hline \multirow[t]{2}{*}{ Region } & east (ref.) & 505 & 2.0 & 1.0 & $1.0,1.0$ & 1.0 & $1.0,1.0$ & 1.0 & $1.0,1.0$ \\
\hline & west & 227 & 2.2 & 1.1 & $0.9,1.3$ & 1.0 & $0.9,1.2$ & 0.2 & $0.1,0.6$ \\
\hline \multirow[t]{8}{*}{ Age $\times$ region } & 55-64, east (ref.) & 25 & 0.2 & & & & & 1.0 & $1.0,1.0$ \\
\hline & 65-74, east (ref.) & 118 & 1.3 & & & & & 1.0 & $1.0,1.0$ \\
\hline & 75-84, east (ref.) & 217 & 5.6 & & & & & 1.0 & $1.0,1.0$ \\
\hline & $85+$, east (ref.) & 145 & 21.4 & & & & & 1.0 & $1.0,1.0$ \\
\hline & 55-64, west (ref.) & 4 & 0.1 & & & & & 1.0 & $1.0,1.0$ \\
\hline & $65-74$, west & 37 & 1.0 & & & & & 3.4 & $1.3,8.8$ \\
\hline & $75-84$, west & 111 & 6.0 & & & & & 4.8 & $1.6,14.9$ \\
\hline & $85+$, west & 75 & 28.2 & & & & & 6.8 & $2.0,22.9$ \\
\hline \multirow{8}{*}{$\begin{array}{l}\text { Gender } \times \\
\text { education }\end{array}$} & M, <1 (ref.) & 84 & 3.1 & & & & & 1.0 & $1.0,1.0$ \\
\hline & M, 1-6 (ref.) & 83 & 1.3 & & & & & 1.0 & $1.0,1.0$ \\
\hline & M, 7-12 (ref.) & 38 & 0.8 & & & & & 1.0 & $1.0,1.0$ \\
\hline & $\mathrm{M},>12$ (ref.) & 13 & 0.5 & & & & & 1.0 & $1.0,1.0$ \\
\hline & $\mathrm{F},<1$ (ref.) & 428 & 4.1 & & & & & 1.0 & $1.0,1.0$ \\
\hline & F, 1-6 & 46 & 0.9 & & & & & 0.8 & $0.4,1.5$ \\
\hline & F, 7-12 & 31 & 1.2 & & & & & 1.8 & $0.9,3.8$ \\
\hline & $\mathrm{F},>12$ & 9 & 1.0 & & & & & 2.1 & $1.1,4.0$ \\
\hline
\end{tabular}

Ref. = Reference category.

${ }^{1}$ All logistic models are based on the full study sample size of $34,807 .{ }^{2}$ Model I adjusts for no additional covariates. ${ }^{3}$ Model II adjusts for age group (4 levels) as a covariate. ${ }^{4}$ Model III covariates (and levels) include age group (4), gender (2), education (4), rural-urban residence (2), marital status (3), ethnicity (2), occupation (6), north-south (NS) contrast (2), east-west (EW) contrast (2), age group-by-EW (8), and gender-by-education (8). 
Table 3. Logistic regression analysis of sociodemographic predictors of vascular dementia in China ${ }^{1}$

\begin{tabular}{|c|c|c|c|c|c|c|c|c|c|}
\hline \multicolumn{2}{|c|}{ Independent variables and effects } & \multirow[t]{2}{*}{$\begin{array}{l}\text { Number } \\
\text { of VaD } \\
\text { cases }\end{array}$} & \multirow[t]{2}{*}{$\begin{array}{l}\text { Prevalence } \\
\text { rate weighted } \\
\text { by cluster } \\
\text { sample, \% }\end{array}$} & \multicolumn{2}{|c|}{$\begin{array}{l}\text { Model I: no covariate } \\
\text { adjustment }^{2}\end{array}$} & \multicolumn{2}{|c|}{$\begin{array}{l}\text { Model II: } \\
\text { age adjusted }^{3}\end{array}$} & \multicolumn{2}{|c|}{$\begin{array}{l}\text { Model III: full covariate } \\
\text { adjustment and } \\
\text { significant }(\mathrm{p}<0.05) \\
\text { interaction terms }\end{array}$} \\
\hline & & & & OR & $95 \% \mathrm{CI}$ & OR & $95 \% \mathrm{CI}$ & OR & $95 \% \mathrm{CI}$ \\
\hline \multirow{4}{*}{$\begin{array}{l}\text { Age group } \\
\text { years }\end{array}$} & 55-64 (ref.) & 59 & 0.4 & 1.0 & $1.0,1.0$ & & & 1.0 & $1.0,1.0$ \\
\hline & $65-74$ & 119 & 0.8 & 2.0 & $1.5,2.7$ & & & 2.0 & $1.0,4.0$ \\
\hline & $75-84$ & 97 & 1.8 & 4.4 & $2.9,6.7$ & & & 8.6 & $5.4,13.8$ \\
\hline & $85+$ & 20 & 1.7 & 4.1 & $2.5,6.8$ & & & 11.1 & $6.3,19.4$ \\
\hline \multirow[t]{2}{*}{ Gender } & male (ref.) & 150 & 0.9 & 1.0 & $1.0,1.0$ & 1.0 & $1.0,1.0$ & 1.0 & $1.0,1.0$ \\
\hline & female & 145 & 0.7 & 0.9 & $0.7,1.1$ & 0.9 & $0.7,1.1$ & 0.8 & $0.6,1.1$ \\
\hline \multirow{4}{*}{$\begin{array}{l}\text { Education } \\
\text { years }\end{array}$} & $<1$ (ref.) & 146 & 1.1 & 1.0 & $1.0,1.0$ & 1.0 & $1.0,1.0$ & 1.0 & $1.0,1.0$ \\
\hline & $1-6$ & 91 & 0.8 & 0.7 & $0.5,0.9$ & 0.8 & $0.6,1.1$ & 0.8 & $0.6,1.1$ \\
\hline & $7-12$ & 45 & 0.6 & 0.6 & $0.3,0.9$ & 0.7 & $0.5,1.2$ & 1.0 & $0.5,1.7$ \\
\hline & $12+$ & 13 & 0.3 & 0.3 & $0.1,0.8$ & 0.4 & $0.1,1.2$ & 0.8 & $0.3,2.2$ \\
\hline \multirow[t]{2}{*}{ Residence } & urban (ref.) & 159 & 0.7 & 1.0 & $1.0,1.0$ & 1.0 & $1.0,1.0$ & 1.0 & $1.0,1.0$ \\
\hline & rural & 136 & 0.9 & 1.3 & $0.9,1.9$ & 1.3 & $0.8,1.9$ & 0.8 & $0.4,1.6$ \\
\hline \multirow{3}{*}{$\begin{array}{l}\text { Marital } \\
\text { status }\end{array}$} & married (ref.) & 217 & 0.8 & 1.0 & $1.0,1.0$ & 1.0 & $1.0,1.0$ & 1.0 & $1.0,1.0$ \\
\hline & widowed & 70 & 0.9 & 1.1 & $0.8,1.5$ & 0.7 & $0.5,0.9$ & 0.6 & $0.5,0.9$ \\
\hline & other & 5 & 0.7 & 0.9 & $0.4,2.2$ & 0.8 & $0.3,2.1$ & 1.0 & $0.4,2.4$ \\
\hline \multirow[t]{2}{*}{ Ethnicity } & Han (ref.) & 292 & 0.8 & 1.0 & $1.0,1.0$ & 1.0 & $1.0,1.0$ & 1.0 & $1.0,1.0$ \\
\hline & other & 3 & 0.5 & 0.6 & $0.3,1.1$ & 0.6 & $0.3,1.2$ & 0.5 & $0.3,1.0$ \\
\hline \multirow[t]{6}{*}{ Occupation } & farm laborer (ref.) & 131 & 1.0 & 1.0 & $1.0,1.0$ & 1.0 & $1.0,1.0$ & 1.0 & $1.0,1.0$ \\
\hline & non-farm laborer & 105 & 0.8 & 0.8 & $0.5,1.2$ & 0.8 & $0.6,1.2$ & 0.6 & $0.3,1.1$ \\
\hline & official & 25 & 0.8 & 0.7 & $0.4,1.4$ & 0.8 & $0.4,1.6$ & 0.5 & $0.2,1.2$ \\
\hline & professional & 10 & 0.1 & 0.1 & $0.1,0.4$ & 0.2 & $0.1,0.5$ & 0.1 & $0.03,0.4$ \\
\hline & sales, service & 5 & 0.5 & 0.5 & $0.1,2.0$ & 0.4 & $0.1,1.9$ & 0.4 & $0.1,1.7$ \\
\hline & housework & 19 & 1.2 & 1.2 & $0.7,2.0$ & 0.9 & $0.5,1.7$ & 0.7 & $0.3,1.5$ \\
\hline \multirow[t]{2}{*}{ Region } & north & 172 & 1.1 & 2.1 & $1.6,2.9$ & 2.5 & $1.9,3.5$ & 4.0 & $2.1,7.7$ \\
\hline & south (ref.) & 123 & 0.5 & 1.0 & $1.0,1.0$ & 1.0 & $1.0,1.0$ & 1.0 & $1.0,1.0$ \\
\hline \multirow[t]{2}{*}{ Region } & east (ref.) & 219 & 0.8 & 1.0 & $1.0,1.0$ & 1.0 & $1.0,1.0$ & 1.0 & $1.0,1.0$ \\
\hline & west & 76 & 0.7 & 0.9 & $0.6,1.2$ & 0.8 & $0.6,1.1$ & 0.8 & $0.6,1.2$ \\
\hline \multirow{8}{*}{$\begin{array}{l}\text { Age } \times \\
\text { region }\end{array}$} & 55-64, south (ref.) & 46 & 0.2 & & & & & 1.0 & $1.0,1.0$ \\
\hline & $65-74$, south (ref.) & 75 & 0.4 & & & & & 1.0 & $1.0,1.0$ \\
\hline & $75-84$, south (ref.) & 46 & 1.4 & & & & & 1.0 & $1.0,1.0$ \\
\hline & $85+$, south (ref.) & 5 & 1.7 & & & & & 1.0 & $1.0,1.0$ \\
\hline & 55-64, north (ref.) & 13 & 0.6 & & & & & 1.0 & $1.0,1.0$ \\
\hline & $65-74$, north & 44 & 1.4 & & & & & 1.0 & $0.5,2.3$ \\
\hline & $75-84$, north & 51 & 2.4 & & & & & 0.4 & $0.2,0.9$ \\
\hline & $85+$, north & 15 & 1.5 & & & & & 0.2 & $0.1,0.5$ \\
\hline
\end{tabular}

Ref $=$ Reference category.

${ }^{1}$ All logistic models are based on the full study sample size of 34,807. ${ }^{2}$ Model I adjusts for no additional covariates. ${ }^{3}$ Model II adjusts for age group (4 levels) as a covariate. ${ }^{4}$ Model III covari- ates (and levels) include age group (4), gender (2), education (4), rural-urban residence (2), marital status (3), ethnicity (2), occupation (6), north-south (NS) contrast (2), east-west (EW) contrast (2), age group-by-NS (8). 


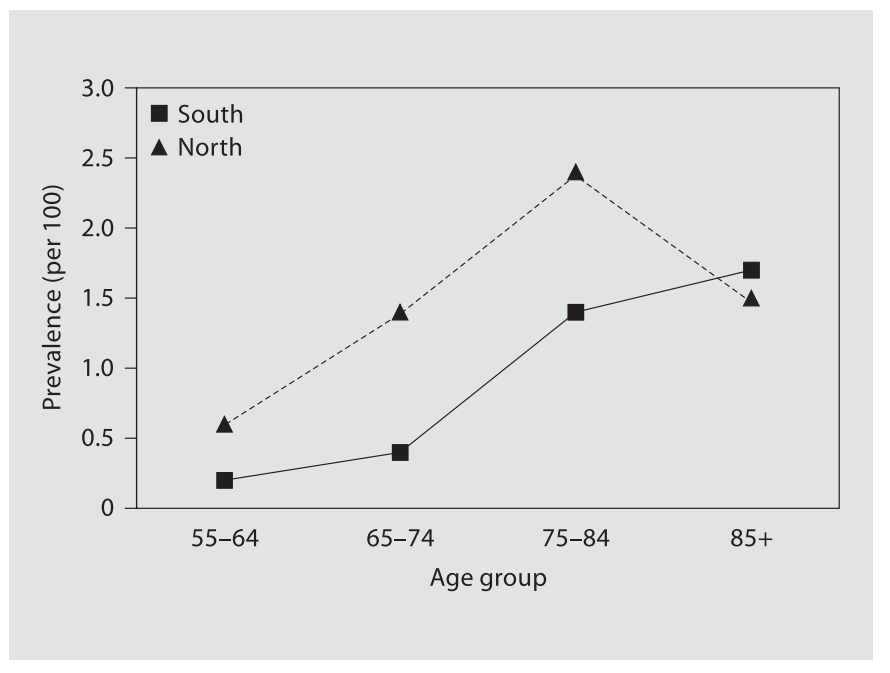

Fig. 1. Age-specific prevalence of $\mathrm{VaD}$, north versus south China.

\section{Socio-Demographic Variation}

Results of the logistic regression models for $\mathrm{AD}$ and VAD are presented in tables 2 and 3, respectively.

\section{Regional Effects}

Significant north-south variation in prevalence was observed for both subtypes, but more pronounced for $\mathrm{VaD}$ than for $\mathrm{AD}$. In crude and age-adjusted associations, the prevalence odds of $\mathrm{VaD}$ was approximately doubled in northern versus southern areas. In the fully-adjusted logistic model with south as a whole reference group, a significant age-region negative interaction was found, whereby $\mathrm{VaD}$ odds in northern areas diminished in the two oldest age groups $\left(\mathrm{pOR}_{\text {full-adj }}=0.4,95 \%\right.$ CI $0.2-0.9$ for age $75-84$ years; $\mathrm{pOR}_{\text {full-adj }}=0.2,95 \%$ CI $0.1-0.5$ for age $85+$ years), suggesting the age-dependent northsouth variation in the prevalence of $\mathrm{VaD}$. This pattern is shown in figure 1, illustrating the age-specific prevalence of $\mathrm{VaD}$ in northern and southern regions.

$\mathrm{AD}$ prevalence odds in northern and southern areas did not differ significantly in crude estimates $\left(\mathrm{pOR}_{\text {unadj. }}=0.8,95 \% \mathrm{CI} 0.7-1.1\right)$; modestly elevated $\mathrm{AD}$ odds were observed in northern regions in adjusted models ( $\mathrm{pOR}_{\text {age-adj }}=1.3,95 \% \mathrm{CI} 1.0-1.7 ; \mathrm{pOR}_{\text {full-adj }}=1.3,95 \%$ CI 1.0-1.7).

The East-West regional variation in prevalence was less pronounced than the north-south contrast, with nonsignificantly lower prevalence odds of $\mathrm{VaD}$ in the west versus the east. West and East China's AD prevalence odds were roughly comparable in crude

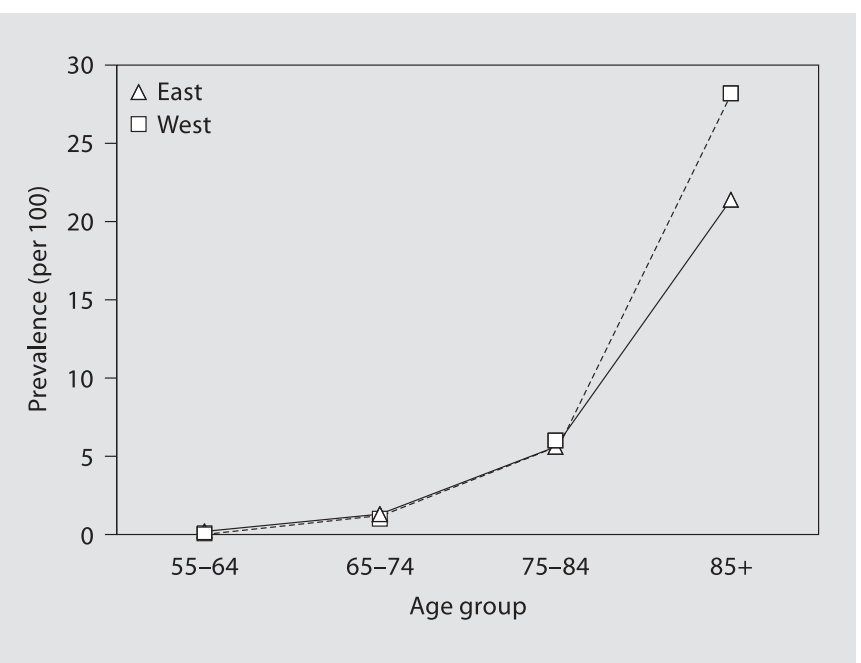

Fig. 2. Age-specific prevalence of $\mathrm{AD}$, west versus east China.

$\left(\mathrm{pOR}_{\text {unadj. }}=1.1,95 \% \mathrm{CI} 0.9-1.3\right)$ and age-adjusted $\left(\mathrm{OR}_{\text {age-adj }}=1.0,95 \% \mathrm{CI} 0.9-1.2\right)$ estimates. With east as a whole reference group, an age-region interaction indicated that $\mathrm{AD}$ prevalence odds increased significantly more rapidly with age in the west. Figure 2 shows the age-specific prevalence of $\mathrm{AD}$ in eastern and western regions of China.

\section{Other Sociodemographic Variation}

Age was the strongest predictor of AD prevalence. We observed sharply increasing odds with each age group after ages 55-64 years. For ages 65-74 $\mathrm{pOR}_{\text {unadj }}=6.7,95 \%$ CI 3.9-11.6; ages 75-84 pOR unadj $=33.1,95 \%$ CI 17.5-62.7; ages 85 and older $\mathrm{pOR}_{\text {unadj }}=164.6,95 \%$ CI 84.25-321.8. The age effects for $\mathrm{VaD}$ prevalence peaked in the 75-84 age group. For ages $65-74 \mathrm{pOR}_{\text {unadj }}=2.0,95 \%$ CI 1.5-2.7; ages 75-84 $\mathrm{pOR}_{\text {unadj }}=4.4,95 \%$ CI 2.9-6.7; ages 85 and older $\mathrm{pOR}_{\mathrm{unadj}}=4.1,95 \%$ CI 2.5-6.8. After full adjustment, age trends for both $\mathrm{AD}$ (table 2) and $\mathrm{VaD}$ (table 3 ) showed significant regional interactions.

Crude and age-adjusted gender differences in prevalence odds were found for $\mathrm{AD}$, showing significantly higher in women than men ( $\mathrm{pOR}_{\text {unadj. }}=2.0,95 \%$ CI $1.5-$ 2.5; $\mathrm{pOR}_{\text {age-adj }}=1.9,95 \% \mathrm{CI} 1.4-2.4$ ). The corresponding $\mathrm{VaD}$ prevalence odds were on average lower for women than men, but not significantly different.

Educated persons had significantly lower AD prevalence odds after controlling for age (1-6 years education $\mathrm{pOR}_{\mathrm{age}-\mathrm{adj}}=0.5,95 \%$ CI $0.4-0.6 ; 7-12$ years education $\mathrm{pOR}_{\text {age-adj }}=0.5,95 \%$ CI $0.4-0.7 ; 12+$ years education 
$\left.\mathrm{pOR}_{\text {age-adj }}=0.4,95 \% \mathrm{CI} 0.2-0.8\right)$. In the model adjusting for all covariates, a significant interaction showed a female preponderance in the group with the highest education (table 2). After age and full-adjustment for socio-demographic confounding, no significant educational effects were observed for $\mathrm{VaD}$.

Rural areas showed modest elevations of AD prevalence compared to urban areas in crude and age-adjusted models ( $\mathrm{pOR}_{\text {unadj. }}=1.5,95 \%$ CI 1.2-1.8; $\mathrm{pOR}_{\text {age-adj }}=1.4$, $95 \%$ CI 1.2-1.7), but no rural-urban differences were observed in the final model controlling for all demographic factors. VaD displayed no significant rural-urban variation.

Widowed persons had significantly higher odds of being prevalent cases of $\mathrm{AD}$ compared to married persons in all models $\left(\mathrm{pOR}_{\text {unadj. }}=5.2,95 \%\right.$ CI 4.0-6.8; $\mathrm{pOR}_{\text {age-adj }}=1.7,95 \%$ CI 1.4-2.2; $\mathrm{pOR}_{\text {fully-adj }}=1.4,95 \%$ CI 1.1-1.7). Although prevalence odds of $\mathrm{VaD}$ among widows did not differ from married persons in crude associations ( $\mathrm{pOR}_{\text {unadj. }}=1.1,95 \%$ CI $0.8-1.5$ ), significantly lower $\mathrm{VaD}$ prevalence odds were observed after adjusting for age $\left(\mathrm{pOR}_{\text {age-adj }}=0.7,95 \%\right.$ CI $\left.0.5-0.9\right)$ and all covariates $\left(\mathrm{pOR}_{\text {age-adj }}=0.6,95 \% \mathrm{CI} 0.5-0.9\right)$.

No significant associations were observed in any model between ethnicity and AD. A significantly lower prevalence of $\mathrm{VaD}$ was observed in ethnic minorities compared to Han after full covariate adjustment $\left(\mathrm{pOR}_{\text {fully-adj }}=0.595 \%\right.$ CI 0.3-1.0).

Occupational effects were detected for both dementia outcomes. For AD, most occupations had lower crude and age-adjusted prevalence odds compared to farm laborers, except housewives (table 2). In the fully-adjusted models, for AD, two occupational groups had significantly or borderline lower prevalence odds than farm laborers: sales-service workers $\left(\mathrm{pOR}_{\text {fully-adj }}=0.4,95 \% \mathrm{CI}\right.$ $0.2-1.0)$ and professional workers $\left(\mathrm{pOR}_{\text {fully-adj }}=0.4,95 \%\right.$ CI 0.2-1.0). For VaD, all occupations showed lower prevalence odds compared to farmers, but these differences were statistically significant only in one group, professional workers $\left(\mathrm{pOR}_{\text {fully-adj }}=0.1,95 \%\right.$ CI $\left.0.03-0.4\right)$.

\section{Discussion}

Our findings indicate that the burden of $\mathrm{AD}$ and $\mathrm{VaD}$ is not distributed equally in all regions and among all sociodemographic groups in China. Although geographic variation in dementia prevalence could result from methodological differences in our study areas, we minimized this potential source of bias through uniform standard- ization of sampling and case ascertainment procedures across sites [18].

Prevalence is a measure of disease burden in populations and is affected by factors such as characteristics of the disease and structure of the population. Prevalence estimates all cases in a population, including incident and surviving cases with onset before data collection. Factors that influence life expectancy, incidence, and prognosis (survival course or case-fatality after onset) will affect prevalence estimates in different areas or population groups. The limited access to CT/MRI may also have affected the relative frequencies of dementia subtypes and contributed to underdiagnosis of $\mathrm{VaD}$, but the present investigation had more use of CT/MRI (50.9\% for $\mathrm{VaD}$ and $6.8 \%$ for $\mathrm{AD}$ ) than all earlier East Asian studies. We attempted to minimize misclassification error by using a final diagnosis of $\mathrm{VaD}$ based on a standardized, multiphase diagnostic algorithm that included a 6-month confirmatory interval, using the NINDS-AIREN criteria. These criteria have low sensitivity but are highly specific for $\mathrm{VaD}$ [43]. In addition, the 6-month clinical evaluations increased the overall diagnostic accuracy. The observed regional variation of $\mathrm{VaD}$ was consistent with the regional patterns of the HIS and the north-south variation in stroke prevalence in China [44]. In summary, the clinical and epidemiological features of $\mathrm{VaD}$ and $\mathrm{AD}$ subtypes observed in this study appear to represent the actual pattern of dementia in China.

Geographic variation of dementia subtypes in East Asia has been attributed to true differences in the underlying risk of disease. Jorm and Jolly [16] observed that East Asian studies exhibited differences in slopes of age curves for dementia, whereby the younger age groups exhibited lower risk than in other regions of the world, but risk increased more rapidly in successive age groups. Suh and Shah [17] hypothesized that regional variation in the ratios of $\mathrm{VaD}$ and $\mathrm{AD}$ in East Asian populations may stem from differences in stroke incidence and risk factors for cerebrovascular disease. He et al. [45] reported that northern cities of China have a threefold higher incidence of stroke than southern China, a fact that may be associated with different exposures to risk factors such as hypertension, higher salt diet, alcohol and cigarette consumption. Vascular risk factors increase the risk of dementia including $\mathrm{AD}$; therefore, these underlying factors may contribute to our observed north-south regional variation of prevalence of dementia subtypes, particularly $\mathrm{VaD}$, and they warrant further epidemiologic study in China.

Western China is less developed than the east, and life expectancy at birth is lower in the west than in the east 
[19]. Consequently the east-west trends observed in our study may reflect a higher case fatality rate following onset of $\mathrm{AD}$ in the youngest age groups, or fewer persons at risk of $\mathrm{AD}$ surviving until the period of onset. More definitive conclusions will depend on further analyses of incidence and mortality rates.

Our study included a high proportion (36.1\%) of illiterate uneducated persons, who were found to have higher prevalence of $\mathrm{AD}$ than educated groups. Numerous epidemiological studies have reported that $\mathrm{AD}$ prevalence is inversely related to education $[46,47]$. In China, education is an important factor in defining social class strata. After controlling for occupational differences, higher education is China is probably a surrogate for health care, nutrition, and lifestyle. Observed differences in patterns of $\mathrm{AD}$ prevalence among educated Chinese men and women in our study might reflect biological differences and/or unique cultural patterns of China. Prior to 1950 , access to education among Chinese women was restricted to the highest social class.

China is mainly an agricultural country with over 700 million rural farmers. At the time of the study, average annual per capita rural incomes were approximately USD 250 [48], and farmers did not have free health care or education. Most non-agricultural occupational groups in this study had lower age-adjusted rates of AD than farmers. Pesticide exposure by rural agricultural workers has been hypothesized to be a possible risk factor for neurodegenerative diseases [49]. Pesticides were unaffordable and rarely used when this elderly population was actively engaged in farm labor, suggesting that limited access to health care, poor nutrition and other factors associated with poverty are more likely to explain the occupational variation in this study.

Selected demographic groups in China appear to have different patterns of $\mathrm{AD}$ and $\mathrm{VaD}$ compared to some Western studies. We did not observe the rural-urban variation reported in European studies [49, 50], which may be partly explained by our use of statistical controls for education and occupation. In addition, no ethnic variation was observed for $\mathrm{AD}$. Ethnic minorities had a significantly lower overall rate of $\mathrm{VaD}$ than the Han Chinese. Differences in diet, cultural patterns, alcohol and tobacco use, quality of living conditions, and health care among ethnic minorities in China are likely to be more important in $\mathrm{VaD}$ than the genetic determinants reported elsewhere [51]. AD prevalence was elevated in China among widows, consistent with Western studies quoting stress and changing social support as underlying factors in cognitive decline [52]. However, lower $\mathrm{VaD}$ prevalence among widows in China has not been previously reported and may reflect survival differences.

The demographic trends used to measure burden of $\mathrm{AD}$ and $\mathrm{VaD}$ in China may be time-sensitive. Improved standards of living and health care may lead to changes in life expectancy and survival in selected population groups, resulting in substantial increases in prevalence of $\mathrm{AD}$ and $\mathrm{VaD}$. Whereas prevalence trends are relatively constant in Western countries, health planners in developing countries may benefit from ongoing monitoring of $\mathrm{AD}$ and $\mathrm{VaD}$ prevalence in different regions and among major demographic groups in coming decades. Enhanced disease surveillance and reporting systems should be coupled with development of innovative, cost-effective systems of care for dementia among vulnerable groups in developing countries.

\section{Acknowledgements}

Supported by grants from the Chinese government (9th 5-year national project 96-096-05-01) and the Chinese Medical Board (CMB) 99-699. The authors would like to acknowledge the assistance of Minyuan Zhang, MD, for training of clinical interviewers.

\section{References}

1 World Health Organization, Population aging: a public health challenge. Fact Sheet No. 135, Revised September 1998.

2 Institute of Medicine, Neurological, Psychiatric, and Developmental Disorders: Meeting the Challenges in the Developing World. Washington, National Academies Press, 2001.

3 Jorm AF, Korten AD, Henderson AS: The prevalence of dementia: a quantitative integration of the literature. Acta Psychiatr Scand 1987;76:465-479.
-4 Fratiglioni L, DeRonchi D, Aguero-Torres H: Worldwide prevalence and incidence of dementia. Drugs Aging 1999;15:365-375.

5 Lobo A, Launer LJ, Fratiglioni L, Andersen K, Di Carlo A, Breteler MM, Copeland JR, Dartigues JF, Jagger C, Martinez-Lage J, Soininen H, Hofman A: Prevalence of dementia and major subtypes in Europe: a collaborative study of population-based cohorts. Neurologic Diseases in the Elderly Research Group. Neurology 2000;54(11 suppl 5):S4-9.
-6 Graves AB, Larson EB, Edland SD, Bowen JD, McCormick WC, McCurry SM, Rice MM, Wenzlow A, Uomoto JM: Prevalence of dementia and its subtypes in the Japanese American population of King County, Washington state. The Kame Project. Am J Epidemiol 1996;144:760-771.

7 Kokmen E, Beard CM, O’Brien PC, Kurland LT: Epidemiology of dementia in Rochester, Minnesota. Mayo Clin Proc 1996;71:275282. 
8 Chen $\mathrm{CH}$, Zhang WX, Shen YC, for collaborative study group for an epidemiological survey of mental disorders in 12 regions: Data analysis for survey on mental disorders, drug-dependent, alcohol-dependent, and personality impairment. Chin J Neurol Psychiatry 1986;19:70-72.

9 Chiu HF, Lam LC, Chi I, et al: Prevalence dementia in Chinese elderly in Hong Kong. Neurology 1998;50:1002-1009.

$>10$ Kua EH: The prevalence of dementia in elderly Chinese. Acta Psychiatr Scand 1991;83: 350-352.

$\checkmark 11$ Li G, Shen YC, Chen CH, et al: A three-year follow-up study of age-related dementia in an urban area of Beijing. Acta Psychiatr Scand 1991;83:99-104.

$\checkmark 12$ Liu HC, Lin KN, Teng EL, et al: Prevalence and subtypes of dementia in Taiwan: a community survey of 5,297 individuals. J Am Geriatr Soc 1995;43:144-149.

13 Wu Z, Meng JM. Wang ML: An epidemiological survey of dementia in the elderly in Changchun Street Area of Beijing. Chin J Neurol Psychiatry 1992;11:131-133.

-14 Zhang M, Katzman R, Salmon D, et al: The prevalence of dementia and Alzheimer's disease in Shanghai, China: impact of age, gender, and education. Ann Neurol 1990;27: 428-437.

15 Hasegawa K, Honma A, Imai Y: An epidemiological study of age-related dementia in the community. Int $\mathrm{J}$ Geriatr Psychiatry 1986;1:45-55.

16 Jorm AF, Jolley D: The incidence of dementia: a meta-analysis. Neurology 1998;51; 728-733.

17 Suh GH, Shah A: A review of the epidemiological transition in dementia: cross-national comparisons of the indices related to Alzheimer's disease and vascular dementia. Acta Psychiatr Scand 2001;104:4-11.

18 Zhang ZX, Zahner GEP, Román G, et al: Dementia subtypes in China: prevalence in Beijing, Xian, Shanghai, and Chengdu. Arch Neurol 2005;62:447-453.

19 Chinese Statistical Yearbook: Beijing, China Statistical Publishing House, 1995.

20 Zhang ZX, Hong X, Li H, et al: The MiniMental State Examination in population aged 55 years and over in urban and rural areas of Beijing. Chin J Neurol 1999;32:149153.

-21 Folstein M, Folstein S, McHugh PR: MiniMental State: a practical method for grading the cognitive state of patients for the clinician. J Psychiatr Res 1975;12:189-198.

-22 Lawton MP, Brody EM: Assessment of older people: self-maintaining and instrumental activities of daily living. Gerontologist 1969; 9:179-186.

23 Chen P, Yu ES, Zhang M, et al: ADL dependence and medical conditions in Chinese older persons: a population-based survey in Shanghai, China. J Am Geriatr Soc 1995;43: 378-383.
24 Zhang MY, Yu E, He YL A: caregiver questionnaire. Shanghai Jingshen Yixue Arch Psychiatry 1995;7(suppl):29-32.

25 Fuld PA: The Fuld Object Memory Evaluation. Chicago, Stoelting Instrument, 1981.

26 Butters N, Granholm E, Salmon DP, et al: Episodic and semantic memory: a comparison of amnesic and demented patients. J Clin Exp Neuropsychol 1987;9:479-497.

27 Wechsler D: Manual: Wechsler Intelligence Scale for Children Revised (WISC-R). New York, Psychological Corporation, 1974.

28 Gong YX: Manual of modified Wechsler Adult Intelligence Scale (WAISRC) (in Chinese). Changsha, China: Hunan Med College, 1982.

29 Morris J: The clinical dementia rating(CDR): current version and scoring rules. Neurology 1993;43:2412-2414.

$30 \mathrm{Xu}$ SL, Wu ZY, Sun CH (eds): Clinical Memory Scale Handbook, Second ed. Psychological Institute, Chinese Academy Science Press, Beijing, 1996:6-104.

31 Solomon PR, Hirschoff A, Kelly B, Relin M, Brush M, DeVeaux RD, Pendlebury WW: A 7 minute neurocognitive screening battery highly sensitive to Alzheimer's disease. Arch Neurol 1998;55:349-355.

32 Hamilton M: A rating scale for depression. J Neurol Neurosurg Psychiatry 1960;23:5662 .

33 Cummings Jeffrey L, Mega M, Gray K, Rosenberg-Thompson S, et al: The Neuropsychiatric Inventory: comprehensive assessment of psychopathology in dementia. Neurology 1994;44:2308-2314.

34 Hachinski V: Cerebral blood flow differentiation of Alzheimer's disease from multi-infarct dementia; in Katzman R, Terry RD, Bick KL (eds): Alzheimer's Disease: Senile Dementia and Related Disorders. Aging. New York, Raven Press, 1978, vol 7, pp $97-$ 104.

35 Reisberg B, Ferris SH, De Leon MJ, et al: The Global Deterioration Scale for Assessment of Primary Degenerative Dementia. Am J Psychiatry 1982;139:1136-1139.

-36 Pfeffer RI, Kurosaki TT, Harrah CH, et al Measurement of functional activities in older adults in the community. J Gerontol 1982; 37:323-329.

37 Zhang MY, Yu E, He YL: A caregiver questionnaire. Shanghai Jingshen Yixue Arch Psychiatry 1995;7(suppl):29-32.

38 McKhann G, Drachman D, Folstein M, et al: Clinical diagnosis of Alzheimer's disease: report of the NINCDS-ADRDA work group under the auspices of the Department of Health \& Human Services Task Force on Alzheimer's disease. Neurology 1984;34: 939-944.
39 Roman GC, Tatemichi TK, Erkinjuntti T, et al: Vascular dementia: diagnostic criteria for research studies. Report of the NINDS-AIREN international workshop. Neurology 1993;43:250-260.

40 American Psychiatric Association: Diagnostic and Statistical Manual of Mental Disorders, ed 4. Washington, American Psychiatric Association, 1994, pp 143-147.

41 World Health Organization: The ICD-10 Classification of Mental and Behavioural Disorders. Diagnostic Criteria for Research. Geneva, World Health Organization, 1993.

42 Research Triangle Institute: SUDAAN User Manual. Release 8.0. Research Triangle Park, Research Triangle Institute, 2001.

43 Gold G, Bouras C, Canuto A, et al: Clinicopathological validation study of four sets of clinical criteria for vascular dementia. Am J Psychiatry 2002;159:82-87.

$44 \mathrm{He}$ J, Klag, MJ, Wu Z, Whelton PK: Stroke in the People's Republic of China. I. Geographic variations in incidence and risk factors. Stroke 1995;26:2222-2227.

$45 \mathrm{He}$ J, Klag, MJ, Wu Z, Whelton PK: Stroke in the People's Republic of China. II. Metaanalysis of hypertension and risk of stroke. Stroke 1995;26:2228-2232.

46 Fratiglioni L, Grut M, Forsell Y: Prevalence of Alzheimer's disease and other dementia in an elderly urban population: relationship with age, sex, and education. Neurology 1991,41:1886-1892.

47 Letenneur L, Launer LJ, Andersen K, et al: Education and the risk for Alzheimer's disease: sex makes a difference. EURODEM pooled analyses. EURODEM Incidence Research Group. Am J Epidemiol 2000;151: 1064-1071.

48 China Statistical Yearbook: Beijing, China Statistical Publishing House, 1998.

49 Keefover RW, Rankin ED, Keyl PM, Wells JC, Martin J, Shaw J: Dementing illnesses in rural populations: the need for research and challenges confronting investigators. J Rural Health 1996;12:178-187.

-50 Rocca WA, Bonaiuto S, Lippi A, Luciani P, Turtu F, Cavarzeran F, Amaducci L: Prevalence of clinically diagnosed Alzheimer's disease and other dementing disorders: a door-to-door survey in Appignano, Macerata Province, Italy. Neurology 1990;40:626631.

51 Green RC, Cupples LA, Go R, et al: Risk of dementia among white and African American relatives of patients with Alzheimer disease. JAMA 2002;287:329-336.

52 Swanwick GR, Coen RF, Maguire CP, Kirby M, Walsh JB, O’Neill D, Coakley D, Lawlor BA: The association between demographic factors, disease severity, and the duration of symptoms at clinical presentation in elderly people with dementia. Ageing 1999;28:295299. 